TITLE: Influence of torrefaction on the grindability and reactivity of woody biomass

AUTHORS: B. Arias, C. Pevida, J. Fermoso, M.G. Plaza, F. Rubiera*, J.J. Pis

ADDRESS: Instituto Nacional del Carbón, CSIC. Apartado 73. 33080 Oviedo, Spain

*Corresponding author: Dr. Fernando Rubiera

Instituto Nacional del Carbón, C.S.I.C.

Apartado 73

33080 Oviedo (Spain)

Telephone: +34 985118975

Fax: +349852976 62

E-mail: frubiera@incar.csic.es 


\title{
Influence of torrefaction on the grindability and reactivity of woody biomass
}

B. Arias, C. Pevida, J. Fermoso, M.G. Plaza, F. Rubiera*, J.J. Pis

Instituto Nacional del Carbón, CSIC. Apartado 73. 33080 Oviedo, Spain

*corresponding author: Tel.: +34 9851189 75; Fax : +34 985297662

E-mail address: frubiera@incar.csic.es

\begin{abstract}
The use of biomass to produce energy is becoming more and more frequent as it helps to achieve a sustainable environmental scenario. However the exploitation of this fuel source does have drawbacks that need to be solved. In this work, the torrefaction of woody biomass (eucalyptus) was studied in order to improve its properties for pulverised systems. The process consists in a heating treatment at moderate temperature (220-300 ${ }^{\circ} \mathrm{C}$ ) under an inert atmosphere. The grindability of raw biomass and the treated samples was compared and an improvement in the grindability characteristics was observed after the torrefaction process. Thermogravimetric analysis of the samples was carried out in order to study their reactivity in air. The DTG curves of the torrefied biomass showed a double peak nature. The kinetic parameters were calculated for each reaction stage. The torrefaction process was found to influence the parameters of the first stage, whereas those corresponding to the second remained unaffected.
\end{abstract}

Keywords: biomass, torrefaction, grindability, thermogravimetric analysis, reactivity. 


\section{Introduction}

One of the current challenges of the European energy network is to reduce its dependence on fossil fuels and to achieve a sustainable environmental scenario.

Renewable energy is a subject of great interest, as it would represent a diversification of the energy sources and contribute to preserving the equilibrium of the ecosystems. In order to achieve this, a target of obtaining $12 \%$ of Europe's primary energy demand from renewable sources by 2010 has been established. Of the different energy sources, biomass holds most promise for increasing use in the next few years. Moreover, biomass is considered as a neutral carbon fuel because the carbon dioxide released during its utilisation is an integral part of the carbon cycle. To increase the fraction of biomass in the energy supply would contribute to diminishing the adverse environmental impact of $\mathrm{CO}_{2}$ and to meeting the targets established in the Kyoto Protocol.

Biomass can be exploited to produce energy by different technologies: thermochemical (combustion, gasification), biological (anaerobic digestion, fermentation) or chemical processes (esterification) (McKendry, 2002). The direct combustion of biomass represents the most promising solution in the short term (Demirbas, 2005). However, the use of raw biomass material as a fuel entails several problems, such as its high bulk volume, high moisture content and relatively low calorific value, which make raw biomass an expensive fuel to transport. For biomass to produce an equivalent amount of energy as fossil fuels such as coal, very high loads of this material would be needed. Another drawback of some types of biomass is that it is difficult to grind if fine particles have to be obtained from lignocellulosic materials. This problem is especially acute when biomass is to be used in pulverised systems, such as cofiring with coal in 
large scale utility boilers. All of these drawbacks have given rise the development of new technologies in order to increase the quality of biomass fuels. One way to deal with some of these difficulties is to produce densified pellets from biomass (Obernberger and Thek, 2004). Another is to improve the properties of biomass by torrefaction or mild pyrolysis. This treatment involves the heating of biomass at moderate temperatures (220-300 ${ }^{\circ} \mathrm{C}$ ) under an inert atmosphere (Bourgeois and Doal, 1984; Lipinsky et al., 2002). Torrefaction is influenced by many parameters that include the composition of the biomass and operation conditions. During the torrefaction of lignocellulosic materials the major reactions of decomposition affect the hemicellulose. Lignin and cellulose may also decompose in the range of temperatures at which torrefaction is normally carried out, but to a lesser degree (Shafizedeh, 1985; Williams and Besler, 1996).

During the torrefaction process the density and the specific heating value of the product increases, and there is a reduction in moisture content. Additionally, torrefied biomass has a hydrophobic nature, so that no moisture is acquired during the storage of the product making fungal degradation unlikely (Hakkou et al., 2006). Another advantage of torrefied biomass is its homogeneity compared with raw biomass, as this contributes to improving the stability of the processes.

Previous researchers have focussed their studies on the mass loss of biomass during torrefaction (Prins et al., 2006a), and the effect of the process conditions on the chemical properties of the product (Prins et al., 2006b; Pentananunt et al., 1990). Less attention has been paid to the grindability (Bergman et al., 2004) or reactivity of torrefied biomass. 
The aim of this work was to study the changes in the grindability characteristics and combustibility behaviour of biomass samples (eucalyptus) when subjected to mild pyrolysis treatment (torrefaction). Grindability was evaluated using a cutting mill, after which the particle size distribution of torrefied biomass was determined. In order to study the thermal characteristics and kinetic parameters, a non-isothermal thermogravimetric analysis of the different samples in air was performed.

\section{Experimental}

The eucalyptus sample was ground and sieved to a particle size of $<5 \mathrm{~mm}$. Torrefaction of the samples was performed using a horizontal quartz reactor with a diameter of 50 $\mathrm{mm}$ and a length of $300 \mathrm{~mm}$. During these tests, $10-15 \mathrm{~g}$ of biomass was heated at a heating rate of $10^{\circ} \mathrm{C} \mathrm{min}{ }^{-1}$ under a nitrogen flow rate of $50 \mathrm{~mL} \mathrm{~min}{ }^{-1}$ up to three different final temperatures $\left(240,260,280^{\circ} \mathrm{C}\right)$. The samples were kept at the final temperature for different residence times (0 to 3 hours). The torrefied biomass samples were denoted as TRE-X-Y, $\mathrm{X}$ indicating the residence time (in hours), and $\mathrm{Y}$ indicating the treatment temperatures (in ${ }^{\circ} \mathrm{C}$ ).

The mass loss of the samples was measured after torrefaction. Proximate and ultimate analyses were performed, and the gross calorific value of the torrefied samples was also determined. The grindability properties of the torrefied biomass were evaluated using a cutting mill with a bottom sieve of $2 \mathrm{~mm}$. After grinding, the samples were sieved to various size fractions in order to evaluate the changes in the grindability of torrefied samples. The samples were examined using an optical microscope.

The thermal behaviour of the samples was studied by means of non-isothermal thermogravimetric analysis. A sample mass $(<450 \mu \mathrm{m})$ of approximately $5 \mathrm{mg}$ was 
heated at a constant rate of $15^{\circ} \mathrm{C} \min ^{-1}$ under an air flow rate of $50 \mathrm{~mL} \mathrm{~min}{ }^{-1}$. A mathematical model was applied to calculate the kinetic parameters of the thermal decomposition of the torrefied biomass in air.

\section{Results and discussion}

\section{Chemical properties}

The variation in the mass yield of the torrefied samples with the final temperature and residence time is shown in Figure 1. The mass yield undergoes an important reduction during the first hour of treatment at the three temperatures studied. Initially, there is a significant mass loss, which is associated with the decomposition of some reactive components of the hemicellulose. At higher residence times, the mass loss can be attributed to the decomposition of the less reactive components of the hemicellulose. This two-step nature of the torrefaction process has been observed by other researchers (Williams and Besler, 1996; Prins et al., 2006a). Temperature plays an important role in torrefaction. At a fixed residence time, the loss in mass yield between 260 and $280{ }^{\circ} \mathrm{C}$ is higher than that between 240 and $260^{\circ} \mathrm{C}$.

The proximate and ultimate analyses, and gross calorific value of the biomass samples are presented in Table 1. This table shows the reduction in volatile matter content of the torrefied biomass with residence time and temperature of treatment. The sulphur content of the samples was below the detection limits and so is not included in the table. The hydrogen and nitrogen content of the samples remained practically unchanged at the torrefaction conditions in this work. Only a slight reduction was detected in the case of hydrogen when torrefaction was carried out at $280{ }^{\circ} \mathrm{C}$. This is due to the fact that 
hydrocarbons, such as $\mathrm{CH}_{4}$ and $\mathrm{C}_{2} \mathrm{H}_{6}$, are only released at higher temperatures than those used in the torrefaction process (Strezov et al., 2006).

The oxygen content of the torrefied samples undergoes a considerable decrease. For instance, the oxygen content of the samples treated at $280{ }^{\circ} \mathrm{C}$ for 3 hours (TRE-3-280) is $26 \%$ less than that of the parent Eucalyptus sample. This decrease is due to the formation and release of $\mathrm{CO}_{2}$ and $\mathrm{CO}$ during the torrefaction process (Prins et al., 2006a; Strezov et al., 2006). The decrease in the O/C ratio improves the gasification properties of the torrefied biomass compared to the raw biomass (Prins et al., 2006c). The heating value of the biomass is an important property, as it will determine its use in energy applications. As can be seen in Table 1, the gross calorific value increases with temperature and residence time. In the most critical conditions ( $280{ }^{\circ} \mathrm{C}$ and 3 hours), the gross calorific value of the product increases by $34 \%$ with respect to the raw biomass. However, during torrefaction, there is a loss of energy with respect to the original biomass that needs to be taken into account. The amount of energy in the torrefied product can be evaluated using the heating value yield, defined in this work as: Heating value yield $(\%)=\frac{M_{f}}{M_{o}} \frac{G C V_{f}}{G C V_{o}} \times 100$ where $\mathrm{M}$ is the mass and GCV the gross calorific value, subscripts $o$ and $f$ referring to the untreated and torrefied biomass respectively.

Figure 2 shows the evolution of the heating value yield of the torrefied samples. The heating value yield ranges from $92 \%$ for the sample treated up to $240{ }^{\circ} \mathrm{C}$ (TRE-0-240) to an extremely low value of $67 \%$ for the sample treated at $280^{\circ} \mathrm{C}$ for 3 hours (TRE-3280). It can be seen from the results depicted in Figure 2 that even at low residence times, the treatment at $280{ }^{\circ} \mathrm{C}$ produces a large decrease in the heating value yield, which does not seem to be counterbalanced by possible improvements in the 
grindability or reactivity characteristics of the biomass. For the other two temperatures (240 and $260^{\circ} \mathrm{C}$ ) the heating value yield remains practically constant from 30 minutes to 2 hours of treatment, with a slight reduction after three hours.

\section{Grindability of torrefied biomass}

In order to evaluate the grindability characteristics of the torrefied Eucalyptus with respect to the original material, the samples were introduced into a cutting mill with a bottom sieve of $2 \mathrm{~mm}$. The ground samples were then sieved into four size fractions: > 425, 425-150, 150-75, and $<75 \mu \mathrm{m}$. The particle size distributions of the torrefied Eucalyptus samples are given in Table 2. The difficulties encountered in reducing the size of the raw biomass are reflected in the results presented in this table, where it can be seen that only $29 \%$ of the untreated biomass passes through the $425 \mu \mathrm{m}$ sieve. In all cases, there is an improvement in the grindability characteristics of the treated biomass, as the percentage of particles passing to the lower size fractions greatly increases for the samples subjected to the torrefaction process. From the grindability results, presented in Table 2 and those of the heating value yield, shown in Figure 2, it seems that a mild torrefaction treatment at $240{ }^{\circ} \mathrm{C}$ for 30 minutes, could improve the grounding characteristics of the biomass with little loss of the heating value.

In order to gain a deeper insight into the modification of biomass by torrefaction, the changes in particle size and shape were observed by optical microscopy. The optical photomicrographs shown in Figure 3 correspond to the particles retained by the $425 \mu \mathrm{m}$ sieve for the untreated and torrefied biomass at six different experimental conditions. For the raw biomass (RE), a highly fibrous nature can be observed in Figure 3, where a mixture of large particles and fibres is observed. The fibres form links between the 
particles and make handling of the raw ground sample difficult. The torrefied biomass samples, on the other hand, present isolated particles and no fibres were detected. As can be observed in Figure 3, the particle size decreases with the rise in temperature and residence time, mainly due to the reduction in length, as the diameter of the particles does not change appreciably with the different conditions. This phenomenon helps to explain the results presented in Table 2 for the particle size distributions of the samples obtained after sieving, since it is the particle diameter (shortest dimension) that determines whether a particle passes through the sieve opening. Thus, the biomass particles become more spherical during the torrefaction process. The problems associated with poor handleabiliby and the poor flow properties of the biomass and coal/biomass blends are well known (Gera et al., 2002; Zulfiqar et al., 2006). In this respect, the results of this work reveal that torrefaction can improve not only the grindability but also the handling characteristics of the biomass, or its ability to flow unhindered through processing and transportation systems.

\section{Non-isothermal thermogravimetric analysis}

In order to evaluate the changes in combustibility produced by torrefaction, the biomass samples were subjected to non-isothermal thermogravimetric tests in air. The rate of mass loss curve of the raw biomass (DTG) is shown in Figure 4. This curve presents a shoulder and two well-defined peaks. The DTG curves of the torrefied biomass samples with no holding time at 240 and $260{ }^{\circ} \mathrm{C}$ (TRE-0-240, TRE-0-260) show a shape similar to that of the raw biomass, while for the rest of the torrefied samples there is a complete lack of shoulder, which is related to the combustion of the hemicellulose components. This can be seen in Figure 4 in the case of the samples treated for one hour at the three 
temperatures. For the treated samples the combustion process takes place in two stages. The maximum DTG values (DTG $\mathrm{Dmax}_{\text {) }}$ and the corresponding peak temperatures for each stage, $T_{1}$ and $T_{2}$, are given in Table 3 . As can be seen, the peak temperatures hardly change, exhibiting values of around 330 and $465^{\circ} \mathrm{C}$, respectively. The fraction of mass loss (excluding moisture) at each stage was calculated by deconvolution of the DTG curves and the results are presented in Table 3. The mass loss during the first stage decreases both with temperature and residence time, while it increases during the second stage. The relation between the volatile matter of the torrefied biomass and the mass loss during the first stage of combustion in the TGA tests has a value of 1.1 . This result indicates that the first peak of the DTG curves of the torrefied samples corresponds mainly to the release and combustion of volatile matter. Other researchers have come to a similar conclusion by comparing the DTG curves from the pyrolysis and combustion of biomass (Skodras et al., 2006).

In order to study the effect of the torrefaction conditions on the reactivity of the products, a mathematical method was used to determine the kinetic parameters. Different methods based on the Arrhenius equation can be applied to obtain kinetic parameters from TGA tests of biomass (Safi et al., 2004). In this work the model proposed by Agrawal and Sivasubramanian (Agrawal and Sivasubramanian, 1987) was used. Assuming a value of 1 for the reaction order, this model gives the following equation:

$$
\ln \left[\frac{-\ln (1-x)}{T^{2}}\right]=\ln \left[\frac{A R}{\beta E_{a}}\left(\frac{1-2\left(R T / E_{a}\right)}{1-5\left(R T / E_{a}\right)^{2}}\right)\right]-\frac{E_{a}}{R T}
$$

where $\mathrm{A}$ is the preexponential factor, $\mathrm{E}_{\mathrm{a}}$ is the activation energy, $\mathrm{R}$ is the universal gas constant and $\beta$ is the heating rate used during the experiments. Due to the two step 
nature of the TGA results, this model was applied independently to both peaks following the methodology used by other researchers (Ghaly et al., 1993; Mansaray and Ghaly, 1993). The activation energies and preexponential factors, calculated by fitting the experimental results, and the initial and final temperatures for the two stages are summarised in Table 4.

The variation in the activation energy of the torrefied samples is shown in Figure 5. For the first stage, there is a clear variation in the activation energy with residence time. The main differences were attained for the samples treated at $240{ }^{\circ} \mathrm{C}$, whereas the samples torrefied at 260 and $280{ }^{\circ} \mathrm{C}$ showed similar values. The activation energies in the second stage display a different trend. This parameter remains almost constant at the different torrefaction conditions, indicating that temperature and residence time exert a negligible effect on the activation energy in the second stage of combustion.

The difference in behaviour can be explained by comparing the range of temperatures of each combustion stage with the different torrefaction temperatures. The range of temperatures at which the first and second combustion stages take place are $235-400^{\circ} \mathrm{C}$ and $400-510{ }^{\circ} \mathrm{C}$, respectively, while torrefaction of the samples is carried out at a maximum temperature of $280{ }^{\circ} \mathrm{C}$. Lignocellulosic biomass is composed of fractions of different thermal stability (hemicellulose, cellulose and lignin). During torrefaction the most reactive fractions (mainly hemicelluloses) are affected, while the others remain stable. Considering the range of temperatures of both stages, it can be assumed that the least reactive fractions will be burned up during the second reaction stage in the nonisothermal TGA tests. As these fractions are not affected during torrefaction, the kinetic parameters of the second stage are practically unaltered, as can be ascertained from the results depicted in Figure 5. 


\section{Conclusions}

The torrefaction of eucalyptus had a great effect on the chemical and grindability properties of the torrefied biomass. The mass yield during torrefaction decreased rapidly during the first hour of treatment, after which it decreased slowly with residence time. A similar behaviour was observed for the heating value yield. The grinding of raw eucalyptus produced a mixture of particles and fibres, whereas only isolated particles were obtained from grinding the torrefied biomass samples. The decrease in particle size was mainly due to the reduction of the particle length.

From the results of this work it can be concluded that the mildest operating conditions for the decomposition of hemicellulose was 30 minutes of residence time at a temperature of $240{ }^{\circ} \mathrm{C}$. At these conditions, the improvement in grindability and handleability characteristics of the torrefied biomass seemed to compensate the mass loss (20\%) and the heating value yield (90\%) attained after torrefaction.

The combustibility curves of the torrefied biomass samples presented two-well defined peaks, which mainly corresponded to the combustion of cellulose and lignite, while the raw eucalyptus also presented a shoulder, due to the evolution of the hemicellulose. The kinetic parameters of the torrefied samples for both reaction stages were determined. The activation energy of the second stage remained practically unaltered due to the relatively low torrefaction temperatures employed, which prevented the thermal decomposition of the less reactive components of the lignocellulosic biomass. 


\section{References}

McKendry, P., 2002. Energy production from biomass (part 2): conversion technologies. Bioresource Technology. 83, 47-54.

Demirbas, A., 2005. Potential applications of renewable energy sources, biomass combustion problems in boiler power systems and combustion related environmental issues. Progress in Energy and Combustion Science. 31, 171-192.

Obernberger, I., Thek ,G., 2004. Physical characterisation and chemical composition of densified biomass fuels with regard to their combustion behaviour. Biomass and Bioenergy. 27, 653-669.

Bourgeois, J.P., Doal, J., 1984. Torrefied wood from temperate and tropical species, advantages and prospects, in: Egneus, H., Ellengard, A. (Eds.), Bioenergy 84, Vol III Biomass Conversion, Elsevier Applied Science Publishers, pp. 153-159.

Lipinsky, E.S., Arcate, J.R., Reed, T.B., 2002 Torrefied wood, an enhanced wood fuel. Fuel Chemistry Division Preprints. 47, 408-410.

Shafizedeh, F., 1985. Pyrolytic reactions and products of biomass, in: Overend, R.P., Milne, T.A., Mudge, L.K. (Eds.), Fundamentals of Biomass Thermochemical Conversion, London: Elsevier; p. 183-217. 
Williams, P.T., Besler, S., 1996. The influence of temperature and heating rate on the slow pyrolysis of biomass. Renewable Energy. 7, 233-250.

Hakkou, M., Pétrissans, M., Gérargin, P., Zoulalian, A., 2006. Investigation of the reasons for fungal durability of heat-treated beech wood. Polymer Degradation and Stability. 91, 393-397.

Prins, M.J., Ptasinski, K.J., Janssen, F.J.J.G., 2006a. Torrefaction of wood. Part1. Weight loss kinetics. Journal of Analytical and Applied Pyrolysis 2006, 77, 28-34.

Prins, M.J., Ptasinski, K.J., Janssen, F.J.J.G., 2006b. Torrefaction of wood. Part2. Analysis of products. Journal of Analytical and Applied Pyrolysis. 77, 35-40.

Pentananunt, R., Mizanur Rahman, A.N.M., Bhattacharya, S.C., 1990. Upgrading of biomass by means of torrefaction. Energy. 15, 1175-1179.

Bergman, P.C.A., Boersma, A.R., Kiel, J.H.A., Prins, M.J., Ptasinski, K.J., Janssen, F.J.J.G., 2004. Torrefaction for entrained-flow gasification of biomass, in: Van Swaaij, W.P.M., Fjällström, T., Helm, P., Grassi, A. (Eds.), Second World Biomass Conference, Rome, Italy, 10-14 May.

Strezov, V.., Patterson, M., Zymla, V., Fisher, K., Evans, T.J., Nelson, P.F., 2007. Fundamental aspects of biomass carbonisation. Journal of Analytical and Applied Pyrolysis. 79, 91-100. 
Prins, M.J., Ptasinski, K.J., Jannsen, F.J.J.G., 2006c. More efficient biomass gasification via torrefaction. Energy. 31, 3458-3470.

Gera, D., Mathur, M.P., Freeman, M.C., Robinson, A., 2002. Effect of large aspect ratio of biomass particles on carbon burnout in a utility boiler. Energy \& Fuels. 16, $1523-1532$.

Zulfiqar, M., Moghtaderi, B., Wall, T.F., 2006. Flow properties of biomass and coal blends. Fuel Processing Technology. 87, 281-288.

Skodras, G., Grammelis, P., Basina, P., Kakaras, E., Sakellaropoulos, G., 2006. Pyrolysis and combustion characteristics of biomass waste-derived feedstock. Ind. Eng. Chem. Res. 45, 3791-3799.

Safi, M.J., Mishra, I.M., Prasad, B., 2004. Global degradation kinetics of pine needles in air. Thermochimica Acta. 412, 155-162.

Agrawal, R.K., Sivasubramanian, M.S., 1987. Integral approximations for nonisothermal kinetics. AIChE Journal. 33, 1212-1214.

Ghaly, A.E., Ergündenler, A., Taweel, A.M., 1993. Determination of the kinetic parameters of oat straw using thermogravimetric analysis. Biomass and Bioenergy. 5, 457-465. 
Mansaray, K.G., Ghaly, A.E., 1993. Determination of kinetic parameters of rice husks in oxygen using thermogravimetric analysis. Biomass and Bioenergy. 17, 19-31. 


\section{List of Tables}

Table 1. Proximate and ultimate analyses, and gross calorific values of the used samples.

Table 2. Particle size distribution of the ground samples.

Table 3. Characteristic parameters from the non-isothermal thermogravimetric tests in air.

Table 4. Kinetic parameters of the torrefied samples from the TGA tests.

\section{List of Figures}

Figure 1. Variation in the mass yield of the torrefied samples.

Figure 2. Variation in the heating value yield of the torrefied samples

Figure 3. Optical photomicrographs of the size fraction $>450 \mu \mathrm{m}$ for the torrefied samples obtained at different experimental conditions.

Figure 4. Evolution of the rate of mass loss during the combustion of the raw and biomass samples torrefied for 1 hour of residence time.

Figure 5. Activation energy of the torrefied biomass samples. 
Table 1. Proximate and ultimate analyses, and gross calorific values of the used samples.

\begin{tabular}{|c|c|c|c|c|c|c|c|c|}
\hline & \multicolumn{3}{|c|}{ Proximate analysis } & \multicolumn{4}{|c|}{ Ultimate analysis* (\% daf) } & \multirow[b]{2}{*}{ G.C.V. (kcal/kg) } \\
\hline Sample & Moisture (\%) & Ash (\%db) & V.M. (\%db) & $\mathrm{C}$ & $\mathrm{H}$ & $\mathrm{N}$ & $\mathrm{O}$ & \\
\hline$\overline{\mathrm{RE}}$ & 6.5 & 0.7 & 84.0 & 49.0 & 6.1 & 0.2 & 44.6 & 4634 \\
\hline TRE-0-240 & 3.5 & 0.5 & 80.5 & 49.2 & 6.2 & 0.2 & 44.3 & 4682 \\
\hline TRE-0.25-240 & 2.7 & 0.5 & 78.7 & 51.2 & 5.9 & 0.1 & 42.7 & 4808 \\
\hline TRE-0.5-240 & 2.1 & 0.7 & 75.4 & 53.1 & 6.1 & 0.1 & 40.6 & 5301 \\
\hline TRE-1-240 & 1.4 & 1.0 & 74.5 & 53.0 & 5.9 & 0.1 & 40.9 & 5195 \\
\hline TRE-2-240 & 2.6 & 0.9 & 73.3 & 54.2 & 5.9 & 0.1 & 39.7 & 5372 \\
\hline TRE-3-240 & 1.3 & 1.0 & 74.1 & 53.8 & 6.0 & 0.1 & 40.0 & 5224 \\
\hline TRE-0-260 & 2.9 & 0.8 & 79.1 & 50.0 & 6.0 & 0.1 & 43.8 & 4697 \\
\hline TRE-0.25-260 & 2.3 & 0.9 & 72.9 & 54.8 & 5.8 & 0.2 & 39.1 & 4918 \\
\hline TRE-0.5-260 & 2.0 & 1.2 & 69.6 & 55.7 & 5.8 & 0.1 & 38.3 & 5425 \\
\hline TRE-1-260 & 1.4 & 0.4 & 69.2 & 55.4 & 5.8 & 0.1 & 38.6 & 5441 \\
\hline TRE-2-260 & 2.8 & 0.9 & 69.5 & 56.2 & 5.9 & 0.2 & 37.6 & 5474 \\
\hline TRE-3-260 & 1.7 & 1.2 & 68.5 & 56.8 & 5.9 & 0.2 & 36.9 & 5556 \\
\hline TRE-0-280 & 2.4 & 0.8 & 76.0 & 57.8 & 5.6 & 0.1 & 36.4 & 4960 \\
\hline TRE-0.25-280 & 2.4 & 0.9 & 69.0 & 57.8 & 5.6 & 0.1 & 36.4 & 5435 \\
\hline TRE-0.5-280 & 1.9 & 1.1 & 67.0 & 57.8 & 5.5 & 0.2 & 35.3 & 5600 \\
\hline TRE-1-280 & 2.1 & 1.6 & 61.5 & 63.5 & 5.3 & 0.2 & 30.9 & 5974 \\
\hline TRE-2-280 & 2.6 & 1.3 & 59.6 & 62.1 & 5.5 & 0.2 & 32.1 & 6026 \\
\hline TRE-3-280 & 1.9 & 1.6 & 60.2 & 60.9 & 5.6 & 0.2 & 33.2 & 6193 \\
\hline
\end{tabular}

db: dry basis

daf: dry ash free basis

* Sulphur content $<0.1 \%$ daf 
Table 2. Particle size distribution of the ground samples.

\begin{tabular}{|c|c|c|c|c|}
\hline Sample & $>425 \mu \mathrm{m}$ & $425-150 \mu \mathrm{m}$ & $150-75 \mu \mathrm{m}$ & $<75 \mu \mathrm{m}$ \\
\hline $\mathrm{RE}$ & 71.2 & 18.7 & 4.7 & 5.4 \\
\hline TRE-0-240 & 55.5 & 32.1 & 8.8 & 3.6 \\
\hline TRE-0.25-240 & 49.9 & 33.5 & 10.8 & 5.8 \\
\hline TRE-0.5-240 & 43.2 & 36.3 & 13.1 & 7.4 \\
\hline TRE-1-240 & 51.9 & 29.9 & 12.2 & 6.0 \\
\hline TRE-2-240 & 42.2 & 37.0 & 12.7 & 8.1 \\
\hline TRE-3-240 & 39.7 & 35.4 & 12.5 & 12.4 \\
\hline TRE-0-260 & 46.8 & 34.1 & 12.3 & 6.8 \\
\hline TRE-0.25-260 & 43.9 & 35.4 & 10.8 & 9.9 \\
\hline TRE-0.5-260 & 37.9 & 34.6 & 13.5 & 14.0 \\
\hline TRE-1-260 & 44.1 & 37.9 & 13.3 & 4.7 \\
\hline TRE-2-260 & 43.6 & 39.5 & 11.4 & 5.5 \\
\hline TRE-3-260 & 35.5 & 35.8 & 18.1 & 10.6 \\
\hline TRE-0-280 & 45.6 & 36.7 & 10.8 & 6.9 \\
\hline TRE-0.25-280 & 45.0 & 35.6 & 11.8 & 7.6 \\
\hline TRE-0.5-280 & 36.2 & 35.6 & 12.7 & 15.5 \\
\hline TRE-1-280 & 46.6 & 35.8 & 12.7 & 4.9 \\
\hline TRE-2-280 & 42.3 & 36.7 & 12.6 & 8.4 \\
\hline TRE-3-280 & 33.9 & 37.0 & 18.8 & 10.3 \\
\hline
\end{tabular}


Table 3. Characteristic parameters from the non-isothermal thermogravimetric tests in air.

\begin{tabular}{|c|c|c|c|c|c|c|}
\hline Sample & DTG max 1 & $\mathrm{~T}_{1}$ & DTG max 2 & $\mathrm{~T}_{2}$ & \% Mass 1 & \% Mass 2 \\
\hline$\overline{\mathrm{RE}}$ & 0.25 & 336 & 0.11 & 461 & 78.7 & 21.3 \\
\hline TRE-0-240 & 0.25 & 331 & 0.13 & 457 & 73.2 & 26.8 \\
\hline TRE-0.25-240 & 0.32 & 338 & 0.14 & 460 & 74.7 & 25.3 \\
\hline TRE-0.5-240 & 0.31 & 335 & 0.14 & 468 & 67.9 & 32.1 \\
\hline TRE-1-240 & 0.29 & 331 & 0.15 & 460 & 66.6 & 33.4 \\
\hline TRE-2-240 & 0.31 & 332 & 0.14 & 467 & 66.0 & 34.0 \\
\hline TRE-3-240 & 0.32 & 336 & 0.14 & 464 & 66.4 & 33.6 \\
\hline TRE-0-260 & 0.24 & 331 & 0.13 & 459 & 72.8 & 27.2 \\
\hline TRE-0.25-260 & 0.30 & 332 & 0.15 & 464 & 63.6 & 36.4 \\
\hline TRE-0.5-260 & 0.29 & 332 & 0.16 & 468 & 61.5 & 38.5 \\
\hline TRE-1-260 & 0.29 & 331 & 0.17 & 464 & 63.7 & 36.3 \\
\hline TRE-2-260 & 0.30 & 332 & 0.15 & 471 & 61.6 & 38.4 \\
\hline TRE-3-260 & 0.27 & 332 & 0.19 & 463 & 57.2 & 42.8 \\
\hline TRE-0-280 & 0.28 & 332 & 0.13 & 467 & 66.2 & 33.8 \\
\hline TRE-0.25-280 & 0.27 & 329 & 0.17 & 469 & 58.9 & 41.1 \\
\hline TRE-0.5-280 & 0.26 & 328 & 0.19 & 468 & 58.9 & 41.1 \\
\hline TRE-1-280 & 0.23 & 328 & 0.19 & 462 & 53.9 & 46.1 \\
\hline TRE-2-280 & 0.2 & 328 & 0.18 & 468 & 53.4 & 46.6 \\
\hline TRE-3-280 & 0.17 & 329 & 0.20 & 470 & 48.4 & 51.6 \\
\hline
\end{tabular}


Table 4. Kinetic parameters of the torrefied samples from the TGA tests.

\begin{tabular}{|c|c|c|c|c|c|c|}
\hline & \multicolumn{3}{|c|}{ First Stage } & \multicolumn{3}{|c|}{ Second Stage } \\
\hline Sample & $\mathrm{T}_{\mathrm{i}}-\mathrm{T}_{\mathrm{f}}$ & Ea $(\mathrm{kJ} / \mathrm{mol})$ & $A\left(\min ^{-1}\right)$ & $\mathrm{T}_{\mathrm{i}}-\mathrm{T}_{\mathrm{f}}$ & Ea $(\mathrm{kJ} / \mathrm{mol})$ & $\mathrm{A}\left(\min ^{-1}\right)$ \\
\hline $\mathrm{RE}$ & $229-400$ & 87 & $1.07 * 10^{7}$ & $400-501$ & 228 & $1.49 * 10^{16}$ \\
\hline TRE-0-240 & $234-396$ & 88 & $1.30 * 10^{7}$ & $396-495$ & 204 & $8.52 * 10^{13}$ \\
\hline TRE-0.25-240 & $237-399$ & 96 & $5.87 * 10^{8}$ & $399-495$ & 195 & $4.98 * 10^{13}$ \\
\hline TRE-0.5-240 & $245-401$ & 100 & $1.25 * 10^{8}$ & $401-495$ & 191 & $2.31 * 10^{13}$ \\
\hline TRE-1-240 & $248-396$ & 106 & $4.10 * 10^{8}$ & $396-501$ & 207 & $1.54 * 10^{15}$ \\
\hline TRE-2-240 & $252-400$ & 119 & $5.13 * 10^{9}$ & $400-501$ & 202 & $1.59 * 10^{14}$ \\
\hline TRE-3-240 & $253-400$ & 119 & $4.62 * 10^{8}$ & $400-498$ & 205 & $2.32 * 10^{14}$ \\
\hline TRE-0-260 & 234-393 & 104 & $2.39 * 10^{8}$ & $393-498$ & 201 & $1.58 * 10^{14}$ \\
\hline TRE-0.25-260 & $249-397$ & 109 & $6.50 * 10^{8}$ & $397-501$ & 193 & $2.80 * 10^{13}$ \\
\hline TRE-0.5-260 & $256-400$ & 114 & $1.59 * 10^{9}$ & $400-501$ & 200 & $9.79 * 10^{13}$ \\
\hline TRE-1-260 & $248-398$ & 113 & $2.58 * 10^{8}$ & $398-501$ & 201 & $1.17 * 10^{15}$ \\
\hline TRE-2-260 & $260-400$ & 125 & $1.28 * 10^{9}$ & $400-508$ & 194 & $4.79 * 10^{13}$ \\
\hline TRE-3-260 & $260-397$ & 133 & $2.52 * 10^{12}$ & $397-499$ & 197 & $6.74 * 10^{13}$ \\
\hline TRE-0-280 & $238-399$ & 110 & $2.96 * 10^{8}$ & $399-502$ & 206 & $3.07 * 10^{14}$ \\
\hline TRE-0.25-280 & 253-399 & 116 & $2.52 * 10^{9}$ & 399-505 & 190 & $1.93 * 10^{13}$ \\
\hline TRE-0.5-280 & $260-398$ & 115 & $2.11 * 10^{9}$ & 398-505 & 196 & $5.83 * 10^{13}$ \\
\hline TRE-1-280 & 260-395 & 119 & $4.50 * 10^{9}$ & $395-501$ & 205 & $2.87 * 10^{14}$ \\
\hline TRE-2-280 & 253-398 & 124 & $8.27 * 10^{9}$ & $398-504$ & 204 & $2.35 * 10^{14}$ \\
\hline TRE-3-280 & 264-397 & 126 & $1.46 * 10^{10}$ & $397-505$ & 200 & $8.45^{*} 10^{13}$ \\
\hline
\end{tabular}




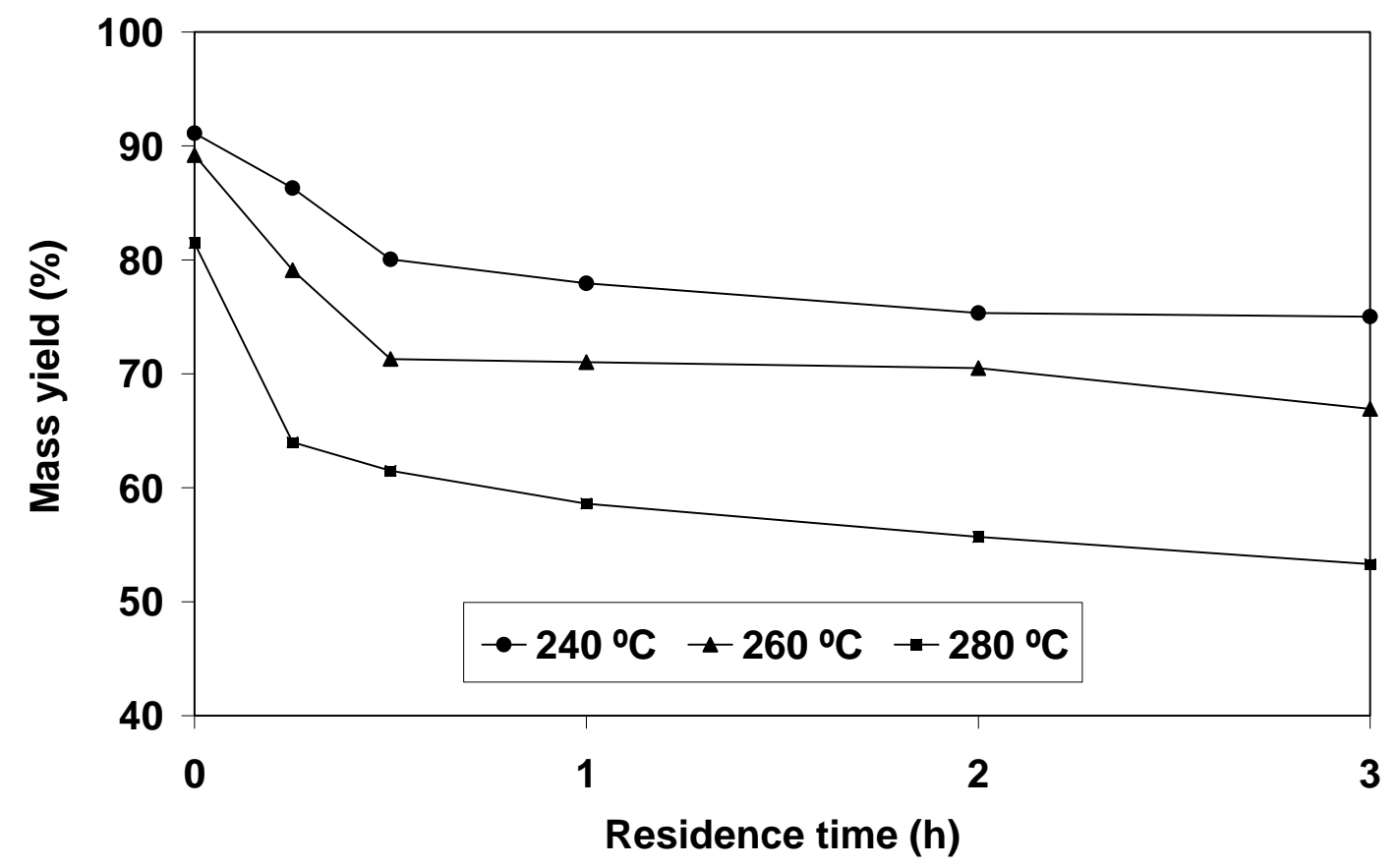

Figure 1. Variation in the mass yield of the torrefied samples. 


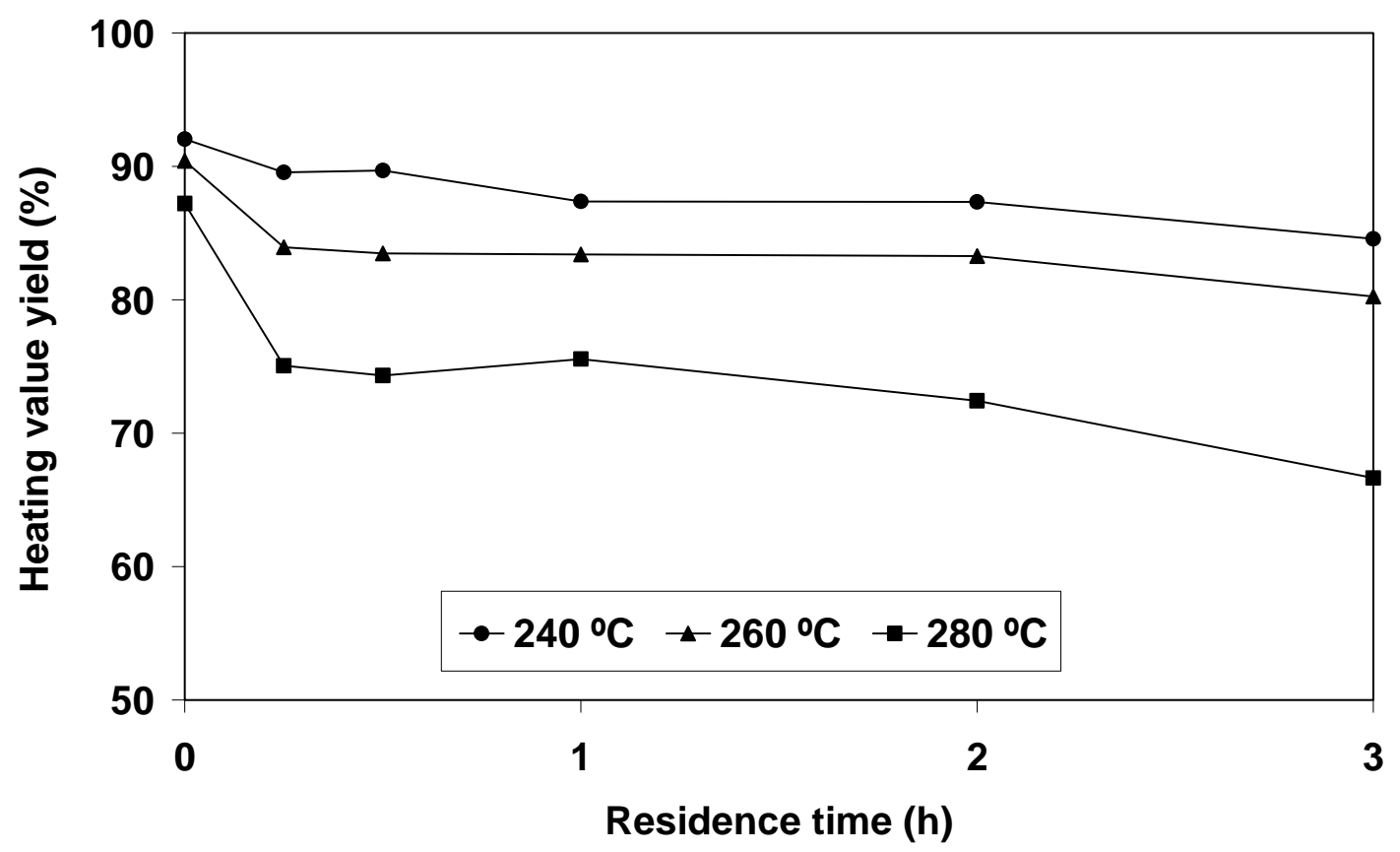

Figure 2. Variation in the heating value yield of the torrefied samples. 

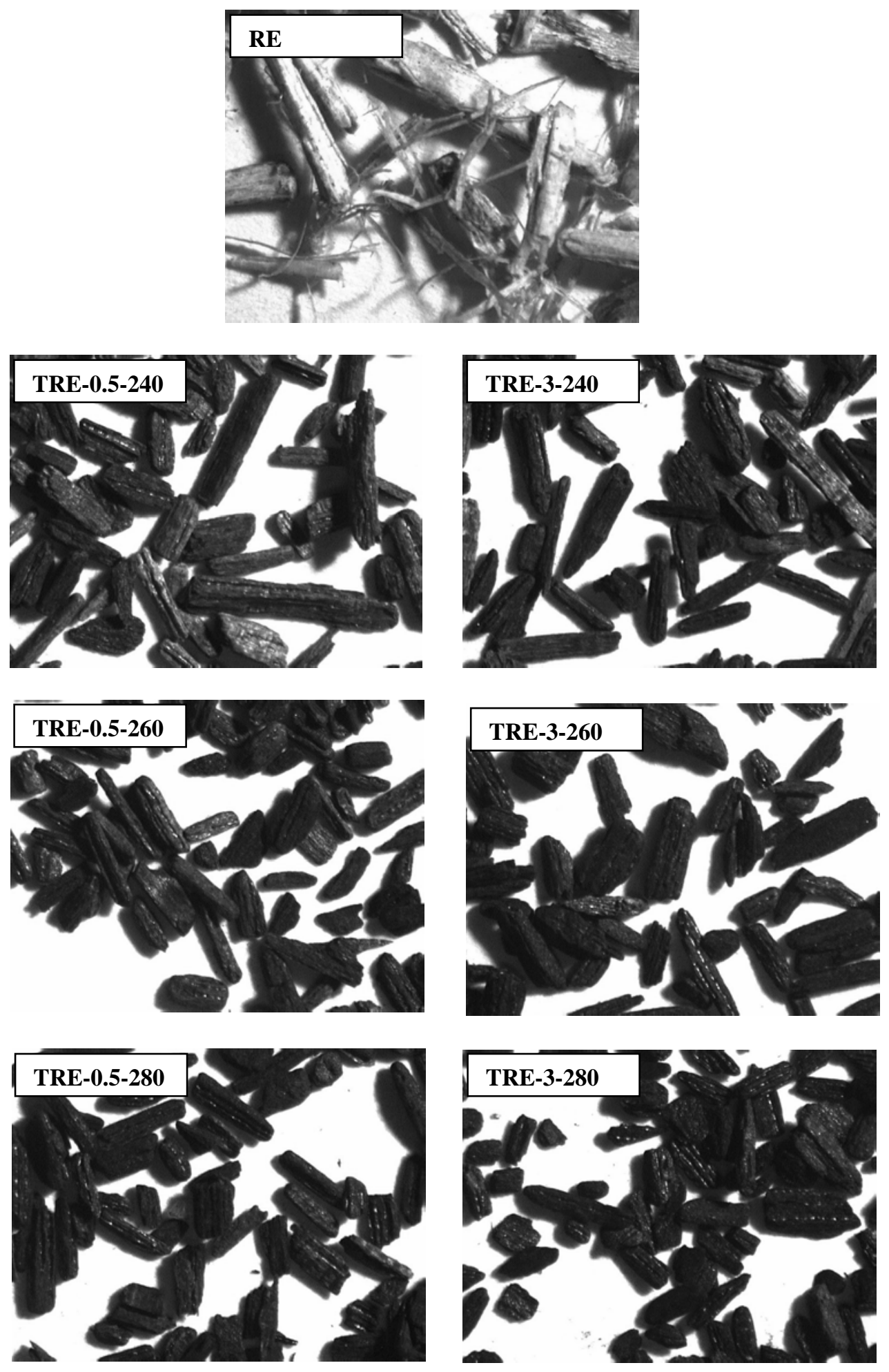

Figure 3. Optical photomicrographs of the size fraction $>450 \mu \mathrm{m}$ for the torrefied samples obtained at different experimental conditions. 


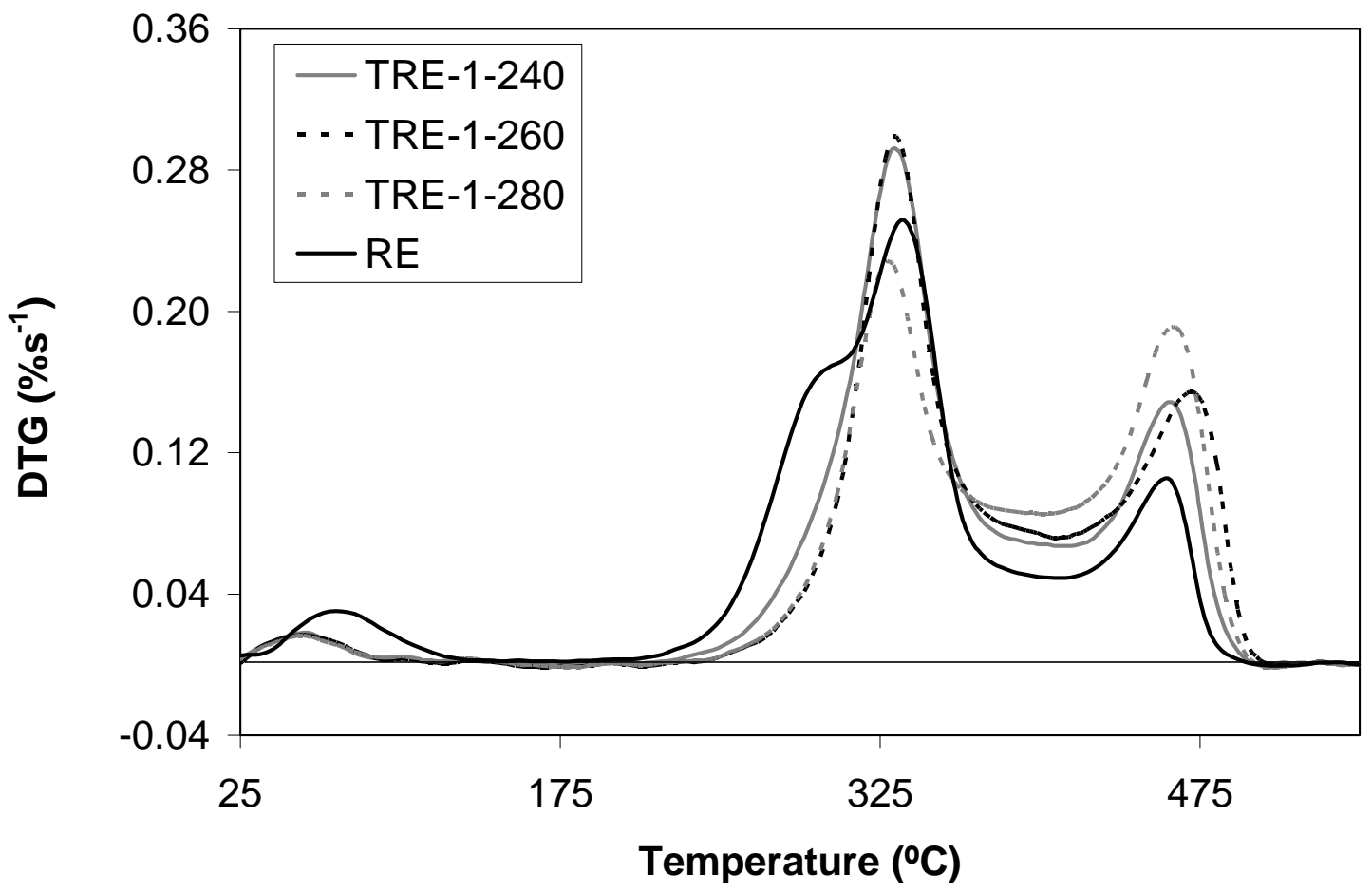

Figure 4. Evolution of the rate of mass loss during the combustion of the raw and biomass samples torrefied for 1 hour of residence time. 


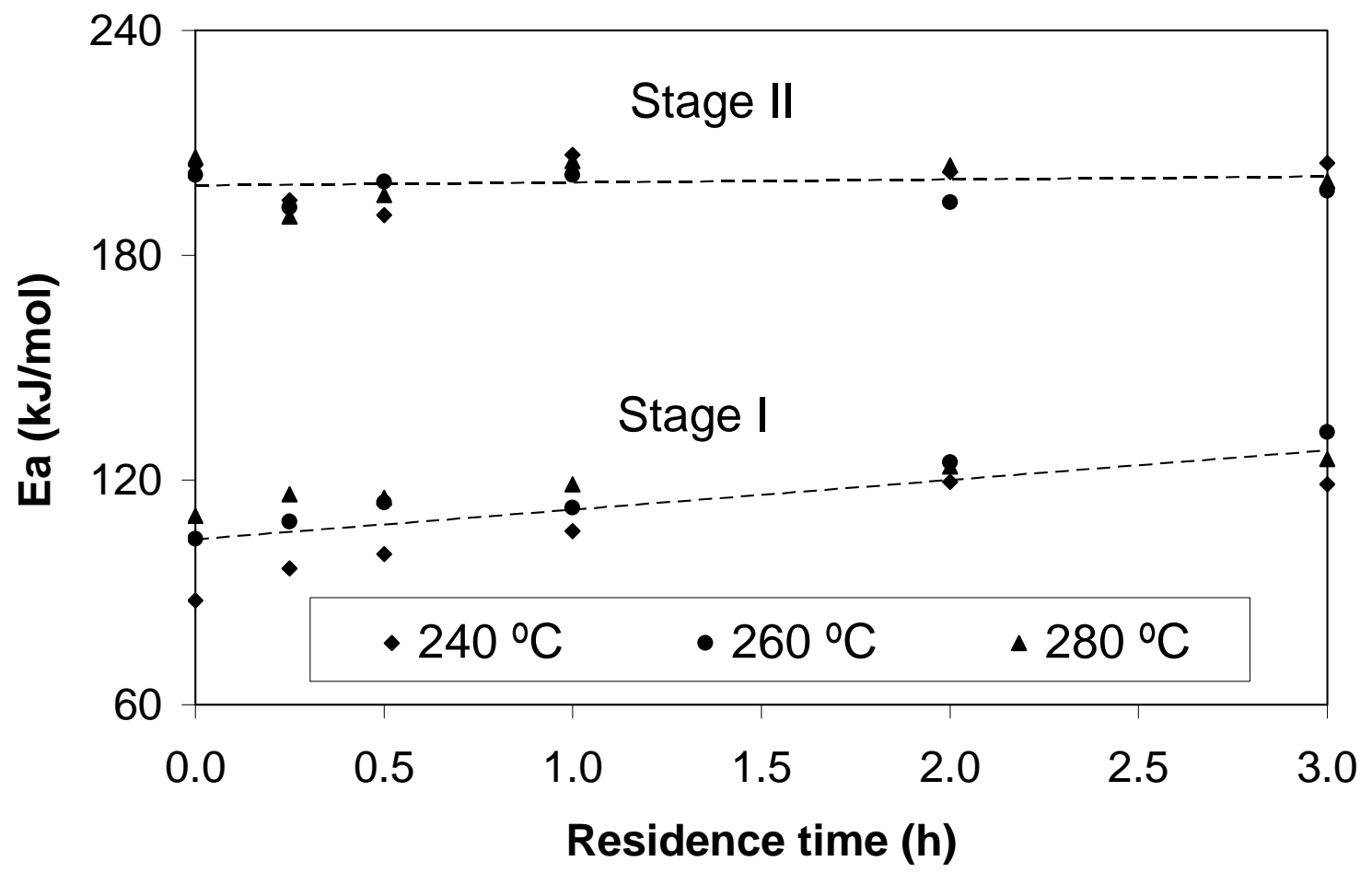

Figure 5. Activation energy of the torrefied biomass samples. 